\title{
Aesthetic Outcome of Gynecomastia Management with Conventional Liposuction and Cross-Chest Liposuction: A Prospective Comparative Study
}

\author{
Ratnakar Singamsetty ${ }^{1} \cdot$ Sunil Kumar Rout ${ }^{1}$ (D) Sanjay Kumar Giri ${ }^{1}$. \\ Ritesh Panda $^{2} \cdot$ Kishore Kumar Behera ${ }^{3} \cdot$ Mukund Namdev Sable $^{4}$
}

Received: 28 June 2021/ Accepted: 19 September 2021/Published online: 12 October 2021

(C) Springer Science+Business Media, LLC, part of Springer Nature and International Society of Aesthetic Plastic Surgery 2021

\begin{abstract}
Background Liposuction is the most accepted technique for treatment of gynecomastia at present with or without residual gland tissue excision. Conventional liposuction uses incisions for introduction of cannula, made usually at the inframammary crease or axilla resulting in consequent scars. Cross-chest liposuction technique was introduced to avoid these additional scars and improve the aesthetic outcome. This study aimed to evaluate the difference between aesthetic outcome of conventional liposuction and cross-chest liposuction in treatment of gynecomastia.

Method A prospective comparative study between 2 groups with 15 patients in each was conducted, one with conventional and the other cross-chest liposuction. Excision of residual gland tissue was performed through circum-areolar incision in both the groups. Aesthetic outcome was evaluated in both the groups using Likert scale and compared.

Result The mean age of the patients was 22.6 years and the mean duration of presentation was 8.13 years. Satisfaction rate with conventional and cross-chest liposuction was $80 \%$ and $86 \%$, respectively, as assessed by the patients. The rate
\end{abstract}

Sunil Kumar Rout

plastic_sunil@aiimsbhubaneswar.edu.in;

drsunilrout@rediffmail.com

1 Department of Burns \& Plastic Surgery, AIIMS, Bhubaneswar, Odisha 751019, India

2 Department of Trauma \& Emergency Medicine, AIIMS, Bhubaneswar, Odisha, India

3 Department of Endocrinology and Metabolism, AIIMS, Bhubaneswar, Odisha, India

4 Department of Pathology \& Laboratory Medicine, AIIMS, Bhubaneswar, Odisha, India was $80 \%$ and $77 \%$, respectively, in both the groups as assessed by independent observer. The complication rate was $13.3 \%$ in conventional and $20 \%$ in cross-chest group. The difference in outcome was not statistically significant between two groups. Difference between the mean Likert scores of pre-operative and post-operative satisfaction was statistically significant for both the techniques.

Conclusion The conventional and the cross-chest liposuction, both yield comparable results when used for treatment of gynecomastia in terms of aesthetic outcome.

Level of Evidence III This journal requires that authors assign a level of evidence to each article. For a full description of these Evidence-Based Medicine ratings, please refer to the Table of Contents or the online Instructions to Authors www.springer.com/00266

Keywords Gynecomastia · Cross-chest liposuction · Aesthetic outcome

\section{Introduction}

Gynecomastia, the diffuse enlargement of male breast represents benign proliferation of glandular male breast tissue. It's prevalence varies between 32 and $65 \%$ in published literature [1]. Etiologically it can be physiological or pathological. Physiological gynecomastia is seen during neonatal period, puberty, and elderly. Pathological condition can have a variety of causes, but majority without any attributable cause or idiopathic. They are divided into florid and non-florid types based on histopathological observations [2]. The pathology persisting for more than two years is unlikely to regress spontaneously or with medical treatment since the tissue by then is irreversibly fibrotic, and surgery remains the mainstay of treatment for these 
cases. The main reasons for which patients seek medical advice are the aesthetic concerns especially unacceptable shape of the chest and body image distortions and fear of breast cancer. Goals of treatment for these conditions include the restoration of normal male pattern chest and nipple-areolar complex with minimal and inconspicuous scars. At present, liposuction is the most preferred surgical modality, alone or in combination with invasive techniques owing to its minimal invasiveness and better contouring principles. Liposuction or suction-assisted lipectomy (SAL), was introduced by Illouz in the 1970 s $[3,4]$. The most common complication with this technique adopted alone for the treatment of gynecomastia is the residual subareolar gland tissue resulting in an unacceptable aesthetic appearance, warranting revision surgery. Also, SAL does not yield promising outcomes in severe and fibrotic cases. However, it is still preferred in large fat predominant breasts because it yields better chest contour with minimal scarring. The suction cannulae are inserted through ports made at inframammary crease or ipsilateral axilla, leaving the scars over those areas as sequel of this procedure. In order to address the residual sub-areolar gland tissue, excision of the same is often used as an additional procedure through a circum-areolar incision. Recently, crosschest liposuction has come up as one of the latest techniques employed in the management of gynecomastia [5]. In this procedure the same circum-areolar incisions are used for both SAL and excision of residual gland tissue, hence doing away with additional scars for the cannula port. This advantage makes it a better choice for the surgeon as well as the patient. In this study, we aimed to compare the aesthetic outcome of conventional liposuction and cross-chest liposuction as an adjunct to sub-areolar gland tissue excision.

\section{Methodology}

\section{Study Design and Study Period}

Present study was a prospective comparative study conducted at an institute of national importance (a tertiary level teaching hospital) of India between January 2019 and December 2020.

\section{Study Population and Eligibility}

After obtaining approval from institute ethics committee (IEC), the study population was taken from patients presenting to the Department of Burns and Plastic Surgery of our institute either directly or referred from other departments, whoever fulfilling the inclusion criteria.

\section{Inclusion Criteria}

- All clinically diagnosed patients of gynecomastia aged between 15 and 50 years, Simon's grade I, II A, and II B [6].

- Persistent pubertal gynecomastia

- Those not resolved with medical therapy

- Those who had a post-operative follow up for a minimum period of 3 months

\section{Exclusion Criteria}

- Patients with physiological gynecomastia

- Those associated with lumps and pseudo-gynecomastia.

\section{Informed Consent}

All the participants were handed over the patient information sheet written in English and local language. Written informed consent was obtained from each participant after explaining about the procedure in the language they can understand.

\section{Sample Size and Group Definition}

Thirty (30) patients were included in this study with 15 in each group. Participants in group 1 were operated by Conventional liposuction technique along with sub-areolar excision of gland. Participants in group 2 were subjected to Cross-chest liposuction technique along with sub-areolar excision of gland.

\section{Randomisation}

Randomisation was done using MS excel tools with RAND function.

\section{Surgical Technique}

For conventional liposuction, the patient was positioned in supine with arms abducted to $90^{\circ}$. The breast tissue on both sides along with periphery was infiltrated with Klein's basic tumescent Solution [7]. This infiltration solution was composed of $500 \mathrm{mg}$ of lidocaine, $0.5 \mathrm{mg}$ of epinephrine, and $10 \mathrm{mEq}$ of sodium bicarbonate in 1 litre of normal saline. A stab incision was made by scalpel in the inframammary fold and used as port for insertion of infiltration as well as suction cannula. Thirty minutes after tumescent infiltration, liposuction was initiated. Depending on the thickness of the adipose tissue layer, liposuction of the deeper layers was performed with a 4-mm cannula, followed by superficial or fine-contouring liposuction using a 
3-mm cannula. Entire breast, as well as its periphery, was treated by this technique. After liposuction, the residual fibro-glandular tissue was extracted from the sub-areolar area via circum-areolar incision extending from 3'O clock to 9'O clock position. A substantial thickness of sub-areolar tissue was left in place in order to maintain the blood supply as well as the contour of the nipple-areolar complex. The procedure was repeated on the opposite side. After securing hemostasis, wounds were closed in layers with negative pressure drains in situ. Patients were advised to put on a front-closure compression vest as early after surgery as feasible for a minimum period of three months.

Cross-chest liposuction was essentially same as described for conventional liposuction. The only difference was the circum-areolar incision being used for suctioning of lateral chest on ipsilateral side and the entire contralateral chest other than its lateral side (Fig. 1).

\section{Outcome Assessment}

The outcome was assessed in terms of satisfaction for eight parameters namely chest appearance, chest circumference, shape, flatness, symmetry, nipple-areolar complex, scars, overall post-operative satisfaction. Each parameter was scored using a 5 point Likert's scale with 1 being very unsatisfied, 5 being very satisfied, and 3 as neutral [8]. The scores were obtained from the patient as well as an independent observer. Comparison was made between the mean Likert scores (LS) obtained by the individual patients before and after treatment, between both the groups as observed by the patients as well as by the independent observer. Mean scores obtained in relation to each individual technique were also compared. Complications observed in each of the groups were recorded and their rate compared.

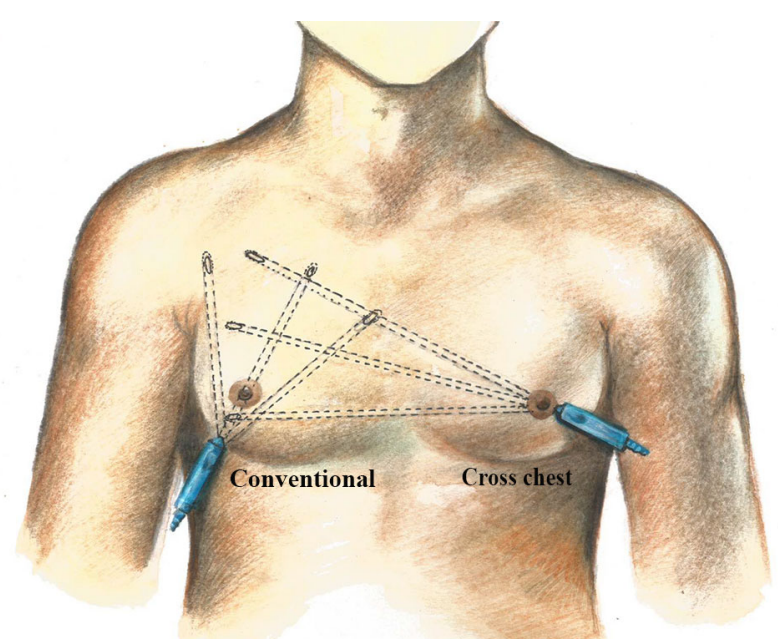

Fig. 1 Schematic diagram of conventional \& cross-chest liposuction

\section{Statistical Analysis}

Continuous numerical data like weight of the gland were expressed in mean $\pm \mathrm{SD}$. Categorical data were expressed in proportions. Ordinal data like Likert scores were expressed in Median. Differences between the groups were analysed by Mann-Whitney $U$ test and Kruskal-Wallis test.

\section{Results}

The total number of cases included in this study was 30 , out of which 15 patients were included in conventional liposuction group and 15 in cross-chest group. Mean postoperative follow-up was 9.2 months for the conventional group and 9.5 months for the cross-chest group. The clinical photographs were taken during each post-operative visit of the patients to our outpatient department and the pictures of the longest follow-up were subjected for assessment in this study. Means and Modes of study variables were calculated using MS Excel tools and the observations mentioned in Table 1.

Mean Likert scores (LS) of the patients were calculated for all the aesthetic parameters and $p$ value was calculated by using student's $t$ test. Mean values were found to be statistically insignificant $(p>0.05)$ for all the parameters from patient's as well as observer's point of view (Tables 2 and 3). Mean Likert scores of pre-operative and post-operative satisfaction were compared by paired $t$ test. Mean Likert score for pre-operative dis(satisfaction) and postoperative satisfaction for conventional technique were 1.66 and 3.8, respectively. The difference was statistically significant $\left(p=01.69121 \times 10^{-6}\right)$. Mean Likert score for preoperative dis(satisfaction) and post-operative satisfaction for cross-chest technique were 1.53 and 3.93, respectively. The difference was statistically significant $(p=$ $01.17679 \times 10^{-6}$ ).

With regard to overall satisfaction, $80 \%$ of patients were satisfied to very satisfied (LS $=4-5$ ) with conventional liposuction and $86 \%$ with cross-chest technique as assessed by the patients. Satisfaction rate was $80 \%$ (LS $=4-5)$ with conventional liposuction and $77 \%$ with cross-chest technique as assessed by independent observer.

Numbness over the operated area and pain was the commonest post-operative complications. Overall, numbness was observed in $13.3 \%$ and pain $3.3 \%$ in our entire study population with a total complication rate of $16.7 \%$. In the conventional, group numbness was present in $6.7 \%$ and pain in $6.7 \%$ (a total of $13.3 \%$ ), whereas the numbness was found to be the only complication $(20 \%)$ with the crosschest group. No one experienced any of the common complications like wound dehiscence, hematoma, or seroma. 
Table 1 Descriptive statistics (mean and modes) of study variables

\begin{tabular}{lllll}
\hline S.no. & Variable & Conventional arm & Cross-chest arm & $p$-value \\
\hline 1 & Mean age (years) & $22.6 \pm 4.13$ & $22.6 \pm 4.13$ & 1.51 \\
2 & Mean duration of illness (years) & $9.33 \pm 2.64$ & $6.93 \pm 2.21$ & 0.001 \\
3 & Simon grade (mode) & II A & II A & NS \\
4 & Mean lipoaspirate (ml) & $201.16 \pm 83.44$ & $150.16 \pm 63.22$ & 0.009 \\
5 & Mean weight of the gland (grams) & $51.54 \mathrm{~g} \pm 32.45$ & $53.42 \pm 24.35$ & 0.42 \\
\hline
\end{tabular}

Table 2 Aesthetic outcome assessed by patient (mean Likert scores)

Table 3 Aesthetic outcome assessed by independent observer (mean Likert scores)

\begin{tabular}{lllll}
\hline S.no. & Variable & Conventional arm & Cross-chest arm & $p$-value \\
\hline 1 & Chest appearance & 3.9 & 3.9 & 1.00 \\
2 & Chest circumference & 3.4 & 3.7 & 0.44 \\
3 & Symmetry & 3.3 & 3.3 & 1.00 \\
4 & NAC & 2.8 & 3.2 & 0.33 \\
5 & Shape & 3.4 & 3.6 & 0.58 \\
6 & Flatness & 3.1 & 3.3 & 0.61 \\
7 & Scars & 2.9 & 3.0 & 0.85 \\
8 & Overall post-op satisfaction & 3.8 & 3.9 & 0.66 \\
\hline
\end{tabular}

\begin{tabular}{lllll}
\hline S.no. & Variable & Conventional arm & Cross chest arm & $p$-value \\
\hline 1 & Chest appearance & 3.9 & 4.0 & 0.79 \\
2 & Chest circumference & 3.8 & 4.2 & 0.60 \\
3 & Symmetry & 3.3 & 3.5 & 0.58 \\
4 & NAC & 3.2 & 3.2 & 0.83 \\
5 & Shape & 3.4 & 3.7 & 0.37 \\
6 & Flatness & 3.5 & 3.8 & 0.31 \\
7 & Scars & 2.8 & 3.2 & 0.27 \\
8 & Overall post-op satisfaction & 3.5 & 3.8 & 0.27 \\
\hline
\end{tabular}

\section{Discussion}

As expected, gynecomastia was observed in our study to be a problem of youth, both physical as well as psychosocial. The mean age of presentation of our patients was $22.6 \pm$ 4.13 years. The mean of the interval between noticing the pathology and seeking medical advice was 8.13 years which indicates, the patients or their parents waited for a reasonable period of time expecting a spontaneous regression. The reason for such delay in some of the cases was found to be futile attempts with prolonged medical treatment or the parents not being convinced about the need for treatment. Whereas, it used to have a significant psychosocial impact on the individuals nurturing this pathology [9-11]. Ordaz DL and Thompson JK in their review, observed gynecomastia to be associated with serious mental disorder causing anxiety, depression, and distortion of body image [12]. The psychological impact of this ailment is clearly evident from our observation of a statistically significant difference between pre-operative (dis)satisfaction and the post-operative satisfaction of patients (Fig. 2), irrespective of the technique used for treatment.

Likert scale was proposed, based on the level of agreement or disagreement responded by the participants to a particular set of questionnaire [8]. This scale is an useful instrument to measure the parameters for outcome assessment of an operative procedure which cannot be quantified objectively. The scale has been used effectively in different studies on this subject by several researchers [13-16]. We too, found this tool very handy and reliable to use for this kind of study. A bias is always expected when the outcome of a surgical procedure is assessed by a member of the operating team. In order to rule out this, we included an independent observer from outside the team with sound anatomical knowledge for outcome assessment, in addition to the patient himself.

The only theoretical advantage of cross-chest liposuction over conventional liposuction in the treatment of gynecomastia is no need for additional incisions to introduce the cannula away from NAC and their consequent 
Fig. 2 Comparison between pre and post-op satisfaction of patients

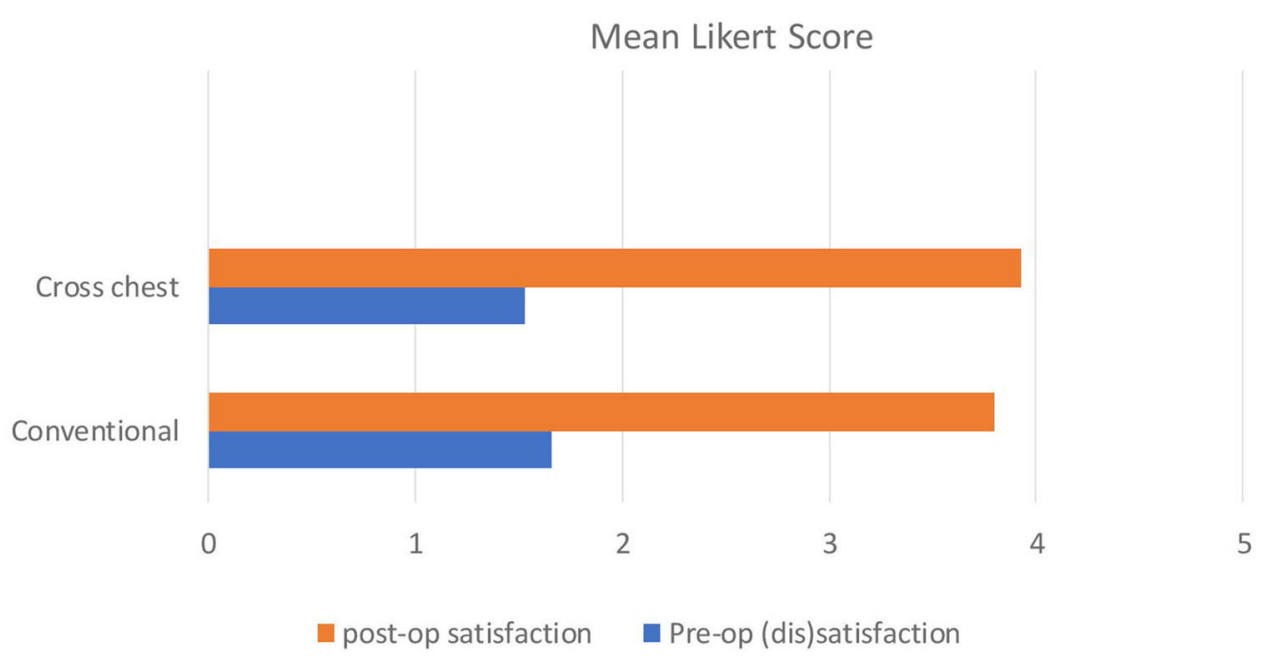


Fig. 4 Bilateral grade II A gynecomastia treated with conventional liposuction

Fig. 5 Bilateral grade II gynecomastia treated with conventional liposuction

Fig. 6 Bilateral grade I gynecomastia treated with cross-chest liposuction
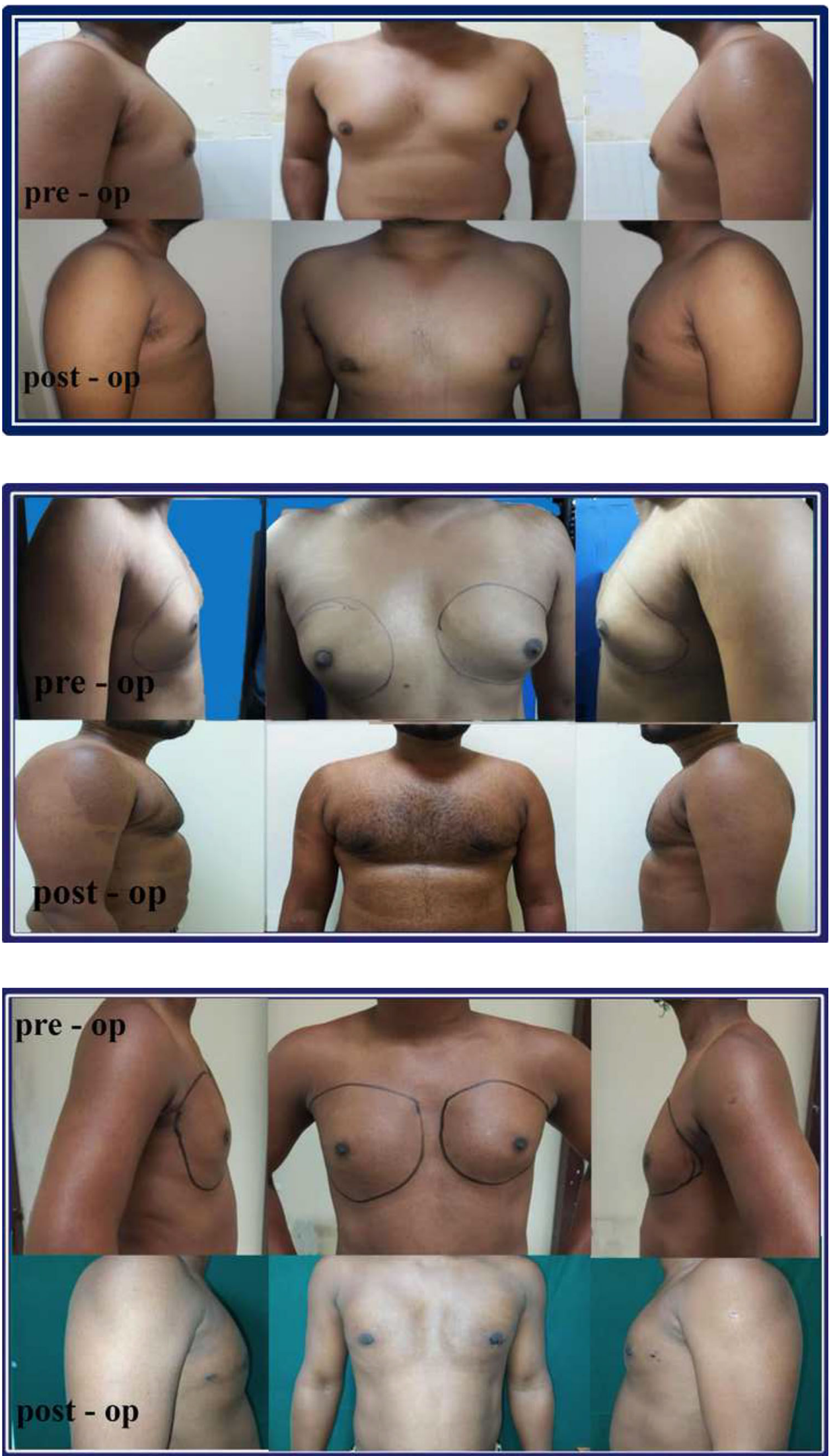
Fig. 7 Bilateral grade II B gynecomastia treated with cross-chest liposuction

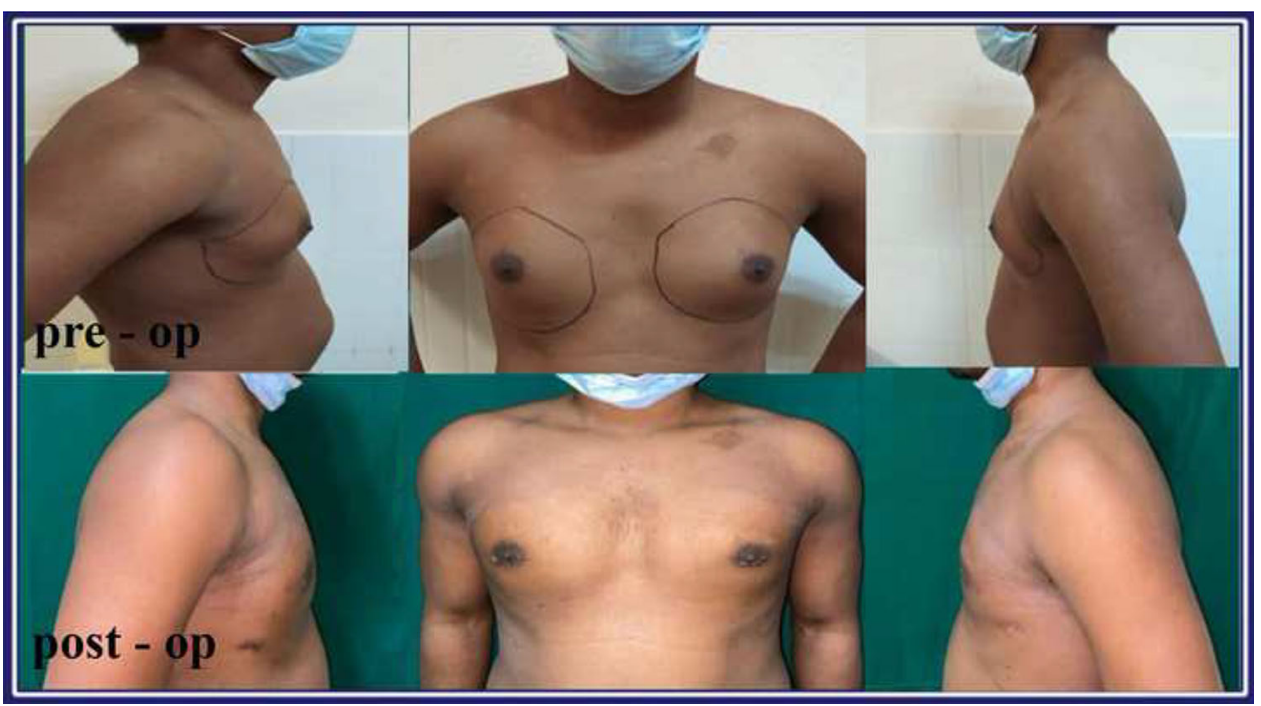

further by future comparative studies with larger sample size.

\section{Conclulsion}

Since there is no difference between two techniques with respect to aesthetic outcome, either the conventional liposuction or the cross-chest liposuction in addition to subareolar gland tissue excision could be considered as an acceptable modality for surgical treatment of gynecomastia.

Acknowledgements We acknowledge the contribution of Dr. Neha Singh as independent observer for this study.

Funding None of the authors in this study has received financial or material support from any source.

\section{Declarations}

Conflict of interest The authors declare that they have no conflict of interest.

Ethical Approval This study was conducted with approval from Institute Ethics Committee and all ethical aspects have been taken care of while conducting this study as per the IEC protocol.

Informed Consent Informed consent was obtained from all participants.

\section{References}

1. Cuhaci N, Polat SB, Evranos B, Ersoy R, Cakir B (2014) Gynecomastia: clinical evaluation and management. Indian $\mathrm{J}$ Endocrinol Metab 18(2):150-158. https://doi.org/10.4103/22308210.129104.PMID:24741509;PMCID:PMC3987263
2. Wiesman IM, Lehman JA, Parker MG, Tantri MD, Wagner DS, Pedersen JC (2004) Gynecomastia: an outcome analysis. Ann Plast Surg 53:97-101

3. Illouz Y-G (1983) Body contouring by lipolysis: a 5-year experience with over 3000 cases. Plast Reconstr Surg 72(5):591-597

4. Bellini E, Grieco MP, Raposio E (2017) A journey through liposuction and liposculture: review. Ann Med Surg (Lond) 6(24):53-60. https://doi.org/10.1016/j.amsu.2017.10.024 (PMID: 29158895; PMCID: PMC5681335)

5. Murali B, Vijayaraghavan S, Kishore P, Iyer S, Jimmy M, Shara M, Paul G, Chavare S (2011) Cross-chest liposuction in gynaecomastia. Indian J Plast Surg 44:81-86

6. Simon BE, Hoffman S, Kahn S (1973) Classification and surgical correction of gynecomastia. Plast Reconstr Surg 51(1):48-52. https://doi.org/10.1097/00006534-197301000-00009 (PMID: 4687568)

7. Klein JA, Jeske DR (2016) Estimated maximal safe dosages of tumescent lidocaine. Anesth Analg 122(5):1350-1359. https:// doi.org/10.1213/ANE.0000000000001119 (PMID: 26895001; PMCID: PMC4830750)

8. Likert R (1932) A technique for the measurement of attitudes. Arch Psychol 140:1-55

9. Nuzzi LC, Cerrato FE, Erikson CR, Webb ML, Rosen H, Walsh EM, DiVasta AD, Greene AK, Labow BI (2013) Psychosocial impact of adolescent gynecomastia: a prospective case-control study. Plast Reconstr Surg 131(4):890-896. doi: https://doi.org/ 10.1097/PRS.0b013e3182818ea8. Erratum in: Plast Reconstr Surg. 2013 May; 131(5):1208. Erikson, Cameron R [corrected to Erickson, Cameron R]. PMID: 23542261

10. Kipling M, Ralph JE, Callanan K (2014) Psychological impact of male breast disorders: literature review and survey results. Breast Care (Basel) 9(1):29-33. https://doi.org/10.1159/000358751 (PMID: 24803884; PMCID: PMC3995375)

11. Rew L, Young C, Harrison T, Caridi R (2015) A systematic review of literature on psychosocial aspects of gynecomastia in adolescents and young men. J Adolesc 43:206-212. https://doi. org/10.1016/j.adolescence.2015.06.007 (Epub 2015 Jul 5 PMID: 26151806)

12. Ordaz DL, Thompson JK (2015) Gynecomastia and psychological functioning: a review of the literature. Body Image 15:141-148. (Epub 2015 Sep 24 PMID: 26408934)

13. Kasielska-Trojan A, Antoszewski B (2017) Gynecomastia surgery-impact on life quality: a prospective case-control study. Ann 
Plast Surg 78(3):264-268. https://doi.org/10.1097/SAP. 0000000000000860 (PMID: 27404477)

14. Innocenti A, Melita D, Mori F, Ciancio F, Innocenti M (2017) Management of gynecomastia in patients with different body types: considerations on 312 consecutive treated cases. Ann Plast Surg 78(5):492-496. https://doi.org/10.1097/SAP. 0000000000000940 (PMID: 27805927; PMCID: PMC5400408)

15. Abdelrahman I, Steinvall I, Mossaad B et al (2018) Evaluation of glandular liposculpture as a single treatment for grades I and II gynaecomastia. Aesth Plast Surg 42:1222-1230. https://doi.org/ 10.1007/s00266-018-1118-x

16. Tarallo M, Di Taranto G, Fallico N, Ribuffo D (2019) The roundthe-clock technique for correction of gynecomastia. Arch Plast Surg 46(3):221-227. https://doi.org/10.5999/aps.2018.00472 (Epub 2019 May 15. PMID: 31113185; PMCID: PMC6536879)

17. Choi BS, Lee SR, Byun GY, Hwang SB, Koo BH (2017) The characteristics and short-term surgical outcomes of adolescent gynecomastia. Aesthet Plast Surg 41(5):1011-1021. https://doi. org/10.1007/s00266-017-0886-Z (Epub 2017 Apr 27 PMID: 28451801)

18. Ridha $\mathrm{H}$ et al (2009) How happy are patients with their gynecomastia reduction surgery. J Plast Reconstr Aesthet Surg 62(11):1473-1478. https://doi.org/10.1016/j.bjps.2008.04.042
19. Chia CT, Neinstein RM, Theodorou SJ (2017) Evidence-based medicine: liposuction. Plast Reconstr Surg 139(1):267e-274e. https://doi.org/10.1097/PRS.0000000000002859

(PMID: 28027260)

20. Taheri AR, Farahvash MR, Fathi HR, Ghanbarzadeh K, Faridniya B (2016) The satisfaction rate among patients and surgeons after periareolar surgical approach to gynecomastia along with liposuction. World J Plast Surg 5(3):287-292 (PMID: 27853693; PMCID: PMC5109391)

21. Walden JL, Schmid RP, Blackwell SJ (2004) Cross-chest lipoplasty and surgical excision for gynecomastia: a 10-year experience. Aesthet Surg J 24(3):216-23. https://doi.org/10.1016/j.asj. 2004.03.005 (PMID: 19336159)

22. Ramon Y, Fodor L, Peled IJ, Eldor L, Egozi D, Ullmann Y (2005) Multimodality gynecomastia repair by cross-chest powerassisted superficial liposuction combined with endoscopicassisted pull-through excision. Ann Plast Surg 55(6):591-594. https://doi.org/10.1097/01.sap.0000189664.88464.34 (PMID: 16327457)

Publisher's Note Springer Nature remains neutral with regard to jurisdictional claims in published maps and institutional affiliations. 